\title{
Heidegger y Zubiri... y el «problema de Dios»
}

\author{
RiCARDO ESPINOZA LOLAS* \\ Pontificia Universidad Católica de Valparaíso (Chile) \\ respinoz@ucv.cl \\ $\mathrm{y}$ \\ PAULA ASCORRA COSTA* ${ }^{*}$ \\ Pontificia Universidad Católica de Valparaíso (Chile) \\ pascorra@ucv.cl
}

\begin{abstract}
Resumen
Lo que este artículo busca es pensar el problema filosófico existencial que se volvió, después de la filosofía de Nietzsche, el tema de Dios como Fundamento a comienzos del siglo XX a la luz de dos grandes pensadores: Heidegger y Zubiri. Por medio de la crisis de fe de Zubiri podemos barruntar lo que le sucedía a toda una época a comienzos de siglo y cómo fue necesaria otra filosofía, la de Heidegger, para poder repensar y vivir la experiencia del Fundamento.
\end{abstract}

Palabras claves: Nietzsche, Heidegger, Zubiri, Fundamento, Dios, Religación.

\section{Heidegger and Zubiri... and the «Problem of God»}

\begin{abstract}
What this article looks is to think the philosophical existential problem that turned, after Nietzsche's philosophy, the God's topic since I Base at the beginning of the 20th century in the light of two big thinkers: Heidegger and Zubiri. By means of the crisis of Zubiri's faith we can feel what was happening to bim to the whole epoch at the beginning of century and how another philosophy was necessary, that of Heidegger, to be able to retbink and live through the experience of the Foundation.
\end{abstract}

Key words: Nietzsche, Heidegger, Zubiri, Foundation, God, religation.

* Doctor en Filosofía por la Universidad Autónoma de Madrid y Catedrático de Historia de la Filosofía Contemporánea de la Pontificia Universidad Católica de Valparaíso. Es Director del Postgrado de Filosofía de la misma universidad y miembro y profesor de la Fundación Xavier Zubiri de Madrid. Autor de más de 23 artículos en torno a Zubiri, también ha escrito los libros Realidad, ser y tiempo en Zubiri (2004), Realidad y tiempo en Zubiri (2006) y Zubiri ante Heidegger (2008).

** Doctora en Psicología por la Universidad de Chile y Catedrática de Psicología Organizacional de la Pontificia Universidad Católica de Valparaíso. Es Jefa de Docencia de la misma universidad. Autora de múltiples artículos en torno a temas organizacionales relacionados con el cuerpo y los afectos.

Este artículo es parte del Proyecto Fondecyt $\mathrm{N}^{\circ}$ 1110507: Realidad y cuerpo en Zubiri. Investigador Responsable: Dr. Ricardo Espinoza Lolas. Alumnos tesistas: Mg. Eugenia Colomer Espinoza y Mg. Ronald Durán Allimant. 


\section{Introducción}

El pensamiento de Nietzsche es un pensamiento que en sí mismo sintetiza toda la Modernidad y lo hace desde un horizonte muy problemático: el problema del fundamento; dicho desde el propio Nietzsche sería el problema del nihilismo o socarronamente y de modo caricaturesco (para molestar a los alemanes) es el problema de Kant y su pensamiento crítico. Para comenzar este artículo, las siguientes palabras del último Nietzsche en su «tristemente célebre» El Anticristo de septiembre de 1888:

-Mirémonos a la cara. Nosotros somos hiperbóreos, - sabemos muy bien cuán aparte vivimos. "Ni por tierra ni por agua encontrarás el camino que conduce a los hiperbóreos"; ya Píndaro supo esto de nosotros. Más allá del norte, del hielo, de la muerte - nuestra vida, nuestra felicidad... Nosotros hemos descubierto la felicidad, nosotros sabemos el camino, nosotros encontramos la salida de milenios enteros de laberinto. ¿Qué otro la ha encontrado? - ¿Acaso el hombre moderno? 'Yo no sé qué hacer; yo soy todo eso que no sabe qué hacer'- suspira el hombre moderno. De esa modernidad hemos estado enfermos, - de paz ambigua, de compromiso cobarde, de toda la virtuosa suciedad propia de sí y el no modernos (Nietzsche, 1990: 27-28).

Nietzsche no es solamente muy franco (algo que al final de su vida en la cordura nos tiene muy acostumbrados) sino que nos coloca de inmediato en el problema de la Modernidad (y en ello de la filosofía misma y de Europa entera). Ella no puede ya ser el horizonte desde donde el hombre, por una parte, dé cuenta de la realidad y, por otra, pueda ser de algún modo feliz (las dos grandes cuestiones que han atravesado el quehacer filosófico desde sus inicios explícitos en Grecia). La Modernidad se ha vuelto nihilista, se ha desfondado, despotenciado a través de tanto fundamento «racional y conceptual» y pesadez del espíritu a través de sus prácticas. Su disputa con Kant (diríamos, «el caso Kant»), esto es, su disputa es contra Alemania y un modo europeo nihilista de ser; lo que podríamos llamar simplemente El caso Modernidad, El caso Europa o, si se quiere, El caso Fundamento, El caso Dios. De allí que Nietzsche sea tan rotundo en sus palabras y nos señala: «Yo no sé qué hacer; yo soy todo eso que no sabe qué hacer - suspira el hombre moderno. De esa modernidad hemos estado enfermos, - de paz ambigua, de compromiso cobarde, de toda la virtuosa suciedad propia de sí y el no modernos». Ya no más el sí y el no modernos, ya no más antinomias, ni dialécticas, en ellos, no hay felicidad sino mera aspiración nihilista a ella, 
a saber, meras «metas» que funcionan como valoraciones negadoras del instante de la vida (de la actualidad de la realidad diría Zubiri) pues se ponen, se establecen por fuera de la misma vida en su ser «instante» (Augenblick); esto es, idealismo y vía teológica que nos sumerge desde la «Cosa en sí» kantiana a la «Idea» hegeliana a dictarnos lo que es la realidad y el hombre; dictum que se agencia siempre a través de algún grupo nihilista que ejerce poder.

Para Nietzsche el pensamiento idealista de la infinitud, del fundamento es imposible para pensar lo propiamente físico del hombre (sin entenderlo dualmente desde el duplo cuerpo-alma) (cf. Ascorra \& Espinoza, 2011) y de las cosas; la vía idealista es la vía teológica, vida que nos lleva a hundirnos más y más en el Ocaso (Untergang) de la oscura noche de la nihilidad, de una nihilidad que emerge con una fuerza tal que todo lo que toca lo neutraliza, lo despotencia y lo niega en lo más radical. ¡He ahí el poder de la «Idea»! Nietzsche lo dice claramente en uno de sus papeles de noviembre de 1887-marzo de 1888:

Lo que cuento es la historia de los próximos dos siglos. Describo lo que viene, lo que ya no puede venir de otra manera: la ascensión del nihilismo. Esta historia ya se puede contar ahora: pues la necesidad misma está aquí trabajando. Este futuro ya habla en cien signos, este destino se anuncia por todas partes; para esta música del futuro ya están aguzados todos los oídos. Toda nuestra cultura europea se mueve desde ya hace tiempo bajo la tortura de una tensión que crece de decenio en decenio como abocada a una catástrofe: inquieta, violenta, precipitada: como un río que quiere acabar, que no reflexiona ya, que tiene miedo de reflexionar sobre sí mismo (Nietzsche, 2006: 489).

Este es precisamente el problema para Nietzsche. La «ascensión del nihilismo» se impone por todas partes; su paso es inexorable y violento como el avance de un desierto. El destino del hombre estará de aquí en adelante ligado al desarrollo mismo del nihilismo; a la evolución del nihilismo «desértico». Europa se vuelve en sí mismo en la historia del nihilismo. ¿Cómo salir de la nihilidad? ¿Es posible salir de ella? Solamente saldremos de ella cuando derribemos a martillazos los ídolos del laberinto de la modernidad. Y cuando se desmorone el laberinto podremos vernos cara a cara con el imponente (e «impotente») minotauro que habitaba y reinaba en él; esto es, ¡Kant! El problema de la modernidad, para Nietzsche, es lisa y llanamente de modo caricaturesco el «problema de Kant» (y es de él donde comienza a darse el problema de 
la infinitud, desde la «Cosa en sí̀ kantiana a la «Idea» hegeliana solamente hay un matiz de diferencia) ${ }^{1}$.

Desde este «martillazo» de Nietzsche a los «Ídolos de Occidente», a la «Historia de Occidente» (no solamente a la filosofía) es desde donde Zubiri se cuestiona filosóficamente la realidad desde comienzos del siglo $\mathrm{XX}$; ese es su horizonte vital ${ }^{2}$. Y de allí surgirá su pronta respuesta siendo muy joven (desde los años veinte del siglo pasado); respuesta que madurará durante los años (hasta la década de los ochenta), pero que será una maduración por profundización a través de y en diálogo crítico con la filosofía de Heidegger. Zubiri ${ }^{3}$ se levanta con todo frente a la Modernidad, es el «problema de la Modernidad»; se levanta también «contra» Kant; incluso podríamos decir que su obra final la trilogía Inteligencia sentiente es una gran crítica a Kant, pues al parecer desde Kant comienza explícitamente, modernamente, la «Historia de un Erron», el cual tiene en Heidegger uno de sus mayores exponentes (esto es

1 La disputa de Nietzsche con Kant se radicaliza a lo largo de los años y en 1888 es una disputa a muerte. Nietzsche que comenzó siendo un «hijo de su tiempo» era kantiano, como la mayoría de su época. Por ejemplo, su gran texto de juventud, escrito que ha marcado a múltiples filósofos posteriores a Nietzsche, Verdad y mentira en sentido extramoral de 1873 (texto posterior al El nacimiento de la tragedia) no es posible entenderlo sino desde la filosofía kantiana, pues es ella la que fundamenta tanto al nihilismo de Schopenhauer como el romanticismo de Wagner. Y contra este pensamiento que se expande por toda Alemania y Europa se rebela Nietzsche; en el fondo, es un ajuste de cuenta con lo más propio de sí. Y en este ajuste de cuentas radica la revisión de la historia misma de Alemania como la de Europa entera. Cuando Nietzsche en 1888 en pleno delirio escribe y escribe, lo que estaba realizando, a toda máquina, era poner en el tribunal a la misma modernidad. ¿Qué tribunal? No es el tribunal de la razón, pues es ella misma, la misma razón de la modernidad la que está siendo juzgada por Nietzsche. El tribunal es el del «cuerpo», es el cuerpo quien juzga la razón moderna: ¡Nietzsche contra la modernidad! Dicho más rotunda y radicalmente: «¿Se me ha comprendido? Dioniso contra el Crucificado...» (Nietzsche, 1980: 132). «Hat man mich verstanden? Dionisos gegen den Gekreuzigten...» (Nietzsche, 1966: 1159).

2 En esto también tenemos que ver la presencia de Ortega, de Bergson, luego de Husserl, pero sobre todo a nivel metodológico en tanto la Fenomenología como una herramienta conceptual y de Heidegger tanto como nueva herramienta conceptual como de las categorías filosóficas mismas del filósofo alemán por medio de su gran libro Sein und Zeit de 1927, pero en especial por los cursos que asistió Zubiri en Freiburg, por ejemplo, Einleitung in die Philosophie (Introducción a la filosofía) de 1928-29, Die Grundbegriffe der Metaphysik. Welt - Endlichkeit - Einsamkeit (Los conceptos fundamentales de la metafísica: mundo, finitud, soledad) de 1929-30. Y también no podemos dejar de señalar cierta lectura de la filosofía griega y alemana que Zubiri aprendió de Heidegger; en especial hay que destacar la lectura heideggeriana de Hegel, desde la Lógica de Jena y de la Fenomenología del espiritu; desde estos textos se leyó no solamente a todo Hegel sino al llamado Idealismo Alemán y con ello de la filosofía europea.

3 Véase Espinoza, 2006: 7. «El pensamiento zubiriano es, en cierta forma, una respuesta afirmativa a la gran crítica nietzscheana a la historia del pensamiento». 
interesante de señalar, pues tanto la actitud de $\mathrm{Hegel}^{4}$ como la de Nietzsche y como la de Zubiri van en una línea similar, al discutir críticamente los supuestos mismos de la Crítica de la razón pura se desmorona no solamente toda la filosofía kantiana sino en cierto sentido la europea). Zubiri es muy explícito en Inteligencia y razón donde señala lo siguiente:

La diferencia entre intelección y conocimiento es un grave problema sobre el que Kant resbaló. Por eso, la Crítica de Kant padece de una radical insuficiencia. Antes de una crítica del conocimiento debió haberse elaborado una crítica, o cuando menos una filosofía de la intelección en cuanto tal. De aquí arranca en última instancia la insuficiencia de la Crítica kantiana. Kant entiende que intelección es conocimiento... Pero Kant entiende además, también sin bacerse cuestión de ello, que en el fondo conocimiento es sinónimo de ciencia. Esta doble ecuación (intelección=conocimiento; y conocimiento=ciencia) determina la marcha de la Crítica kantiana. Pero esta doble ecuación no es exacta. $\mathrm{Ni}$ intelección es conocimiento, ni la estructura del conocimiento es ciencia [el subrayado es nuestro]» (Zubiri, 1983: 159-160).

Esa doble ecuación kantiana, esto es, intelección = conocimiento y conocimiento $=$ ciencia es la que radicalmente ataca y desmantela Nietzsche en su obra y en especial al final de su vida filosófica (y esto no lo podemos olvidar para leer libros tan complejos, difíciles, molestos y duros como, por ejemplo, Asi habló Zaratustra, Genealogía de la moral, El Anticristo). Pues la intelección no es conocimiento sino experiencia sentiente del hombre inmerso en la realidad y por ello «luego» conoce. Y también creer que el conocimiento se reduce a la ciencia es de todo formalmente falso. Por eso para Nietzsche (como también para Hegel, Heidegger y obviamente Zubiri y tantos otros filósofos) antes de una ciencia estricta de base anglosajona y que se mueve en el instrumento y la medida de lo que se da como objeto prefiere hablar de una «ciencia festiva». El conocimiento es mucho más amplio que un modelo de ciencia determinado para «medir la Naturaleza». Y finalmente debiéramos añadir que analizar y dar martillazos a Kant, es decir, El caso Kant (Lutero, Wagner, etc.), es dar martillazos no solamente a la filosofía

\footnotetext{
4 El pensamiento paralizante del kantismo, el miedo a errar, como dice magistralmente Hegel en la Introducción a la Fenomenología del espiritu, es un miedo radical a la verdad, a esa verdad que nos arrastra con la necesidad lógica de la vida más propia de cada uno. Véase Hegel, 2010: 145. «... la preocupación por caer en el error desconfía de toda ciencia que se ponga manos a la obra sin reservas de ese estilo y conozca efectivamente, no se ve por qué no ha de ser a la inversa, y desconfiar de esa desconfianza, preocupándose de que este temor a errar sea ya el error mismo... lo que se llamaba temor al error se da a conocer, más bien, como temor a la verdad».
} 
(esto es lo que menos le interesa a Nietzsche) sino al arte, a la teología, a la ética, a la política, etc., a saber, a todo un modo de comprender la realidad en general desde el problema del fundamento. Pero no olvidemos que tanto Nietzsche como Zubiri fueron muy «kantianos»al comienzo de su periplo filosófico y este rasgo «kantiano» siempre los persiguió, como un espectro, hasta el final de sus días; ellos también se movieron en la escisión entre realidad y hombre.

\section{1. «La duda»}

Cuando oí que el Obispo nos invitaba a dar el paso decisivo me adelanté sin titubear; nos prosternamos ante el altar; se cantaron sobre nosotros las letanías de los santos: el gran error de mi vida estaba consumado. Tenía miedo de haber sacrificado mi vida a la nada (Carta de Xavier Zubiri a L. Eijo y Garay, 19-3-1922) (Corominas \& Vicens, 2006: 721).

Por medio de la última biografía de Zubiri titulada: Xavier Zubiri. La soledad sonora de Jordi Corominas y Joan Albert Vicens los estudios actuales acerca de Zubiri han cambiado; ya no es lo mismo afirmar lo que se decía cuando se interpretaba la filosofía de Zubiri sin saber varios asuntos personales de la biografía existencial del filósofo. Muchos estudios han envejecido, otros nos parecen errados en sus orientaciones, algunos radicalmente equivocados y otros, la mayoría, superficiales. Por lo general, se empezaba a estudiar el pensamiento de Zubiri desde su primer libro Naturaleza, Historia, Dios (libro que es una compilación realizada por el propio autor de distintos trabajos suyos entre los años 1933-1944); tal libro fue publicado en 1944 cuando el filósofo ya tenía unos 45 años de edad. Por tanto, era obvio que mucha «agua bajo el puente» había pasado en la vida ya biográfica como intelectual y que no se tenía del todo considerada para una aproximación más radical del autor.

La Biografía de Zubiri constituye en sí misma un antes y un después para la investigación científica del autor; algo similar a lo que aconteció con la biografía de Descartes, de Nietzsche, de Heidegger y en especial eso sucede con los grandes autores. Por fin podemos saber o confirmar lo que ya intuíamos de Zubiri, a través de nuestros estudios, en lo más propio de su vida y en particular a lo sucedido antes de la publicación de Naturaleza, Historia, Dios, pues esto era muy relevante, ya que ahí, más que por lo anecdótico de una vida personal, se fraguó el pensamiento filosófico maduro del autor. Nos faltaba el «temple fundamental» desde donde se levantó el filosofar zubiriano y ese temple era el dejado y 
expresado de modo tan radical por el siglo XIX. Zubiri era un joven pensador de los albores del siglo XX; un joven nacido desde el horizonte del nihilismo; el cual ya había «ascendido» con toda su fría majestuosidad.

Por esta razón, un problema, por ejemplo, que es fundamental en Zubiri ( $y$ en cierto sentido el único tema que enraíza todo su pensamiento) a lo largo de su vida como filósofo es el tema de Dios (que es el problema del fundamento que constituye el horizonte del nihilismo), ya que este tema atraviesa toda su obra en distintos niveles. Se han publicado varios inéditos del pensador español que son estudios en torno al problema de Dios (incluso se ha identificado a Zubiri como un filósofo de las religiones, al estilo de Mircea Eliade o, simplemente como un filósofo «cristiano»; un neotomista como Etienne Gilson); se han realizado muchos artículos, monografías, libros, etc. de distintos estudiosos que investigan el pensamiento de Zubiri en torno al fenómeno religioso, pero solamente ahora nos podemos hacer cargo de la génesis misma de este problema; y en ello creemos que las siguientes palabras tan sentidas y vividas de un joven filósofo español de 23 años de edad pueden ser buen modelo para comenzar a repensar lo más propio de este pensamiento; pensamiento, como hemos dicho, incardinado en su propio horizonte, el horizonte europeo del nihilismo:

El Evangelio toma ante la vida presente una actitud de desprecio para no mirar más que a la vida futura. Se nos pone como modelo a Jesús, y hay que tener un poco de buena voluntad para creer que aprecia la vida presente quien dice que no tiene donde recostar su cabeza. Lógicamente interpretado, el Evangelio tiende a hacer del mundo una cartuja en la que los habitantes esperan el advenimiento de la vida futura. La concepción de la vida debe ser la contraria. Se la debe considerar como el gran bien que por el momento poseemos, y nuestro primer imperativo es desarrollar positivamente esta vida. Una cartuja es en el fondo un acto de fe en el budismo. La vida no debe organizarse en fúnebre comitiva que se dirige a la eternidad; la vida es una conquista de la felicidad inmanente», Carta de X. Zubiri a L. Eijo y Garay (19-3-1922) (Corominas \& Vicens, 2006: 144145).

Estas palabras pueden dejar perplejos a muchos que filosofan en estos tiempos, pues al parecer «Dios» ya no es tema para el pensamiento actual (por ejemplo, para Jameson, Zizek, Rancièré), menos un «problema» que conmueva toda nuestra existencia. Además, pueden sonar estas frases como palabras de un Nietzsche (de su última etapa; la más radical), pero están dichas por Zubiri en su juventud; escritas en una extensa carta autobiográfica el día 19 de marzo de 1922. Son palabras que surgen del corazón mismo del pensador y pueden sonar tan extrañas 
para muchos que se acercaron a la obra de Zubiri desde Naturaleza, Historia, Dios, esto es, desde una obra que fue publicada en 1944 y bajo un horizonte ontológico heideggeriano. Es decir a 22 años después de esas palabras del joven filósofo. Y si pensamos en esos lectores, que son muchos, que han llegado en estos últimos años a estudiar a Zubiri desde el horizonte abierto por su gran trilogía de la inteligencia titulada: Inteligencia sentiente (1980-1983); para ellos les puede sonar absolutamente extraño esas «añejas» palabras del filósofo de la actualidad, de la formalidad de realidad, del «de suyo», etc. En estos últimos textos se puede ver, aparentemente, que explícitamente no aparece Dios, ni como problema.

A Zubiri a lo largo de las décadas ya en España, ya en Latinoamérica se le ha leído de múltiples formas. Unas veces como neoescolástico, otras como fenomenólogo, otras como heideggeriano, algunas veces como filósofo de las ciencias, otras como filósofo de las religiones, unas como «el» discípulo de Ortega, otras como «el» maestro de Ellacuría, unas como filósofo "cristiano», otras como un «metafísico», etc., etc. Ahora creemos que también es legítimo leer a Zubiri como cierto «vitalista» (desde Nietzsche, Bergson, Ortega); en cierta forma, Zubiri es otro filósofo del martillo; de allí su radicalidad para pensar y repensar los mismos problemas de siempre: el hombre, la Naturaleza y Dios: «En su juventud, Zubiri recitaba de memoria en alemán, como jaculatorias antes de una larga travesía, fragmentos de la obra de Nietzsche Así habló Zaratustra. Al final de su singladura, en los últimos años de su vida, le gustaba declamar solemne las primeras líneas del libro: «Yo estoy saciado de sabiduría como la abeja que ha recogido demasiada miel y tengo necesidad de manos que se extiendan. ¡Bendice, oh Sol, la copa que quiere desbordarse para que de ella fluya el agua de oro llevando a todas partes el resplandor de tus delicias» (Corominas \& Vicens, 2006: 21).

Zubiri vivió «en torno al problema de Dios» (el problema del fundamento en el horizonte del nihilismo). Al igual que toda una pléyade de pensadores europeos en una época de cambios absolutamente vertiginosos; desde el siglo XIX al XX el hombre se vuelve en un «tránsito» (Übergang), un tránsito por el «Ocaso» (Untergang) del siglo. Desde Nietzsche (y tendríamos que pensar en esos dos gigantes del pensamiento que lo precedieron que fueron Schelling y Hegel) a Heidegger, pasando por Kierkegaard, Marx, Dilthey, Bergson, Unamuno, Freud, etc., Dios era sentido como el problema de Dios. Un problema que constituía las entrañas mismas de Europa. Ya con Nietzsche sabíamos que ni la metafísica ni la teoría del conocimiento podrían ser lo que fueron por tantos siglos pues el problema del objeto y del sujeto ha caído rotundamente de su pedestal. La realidad no se dejaba atrapar en 
categorías metafísicas de ninguna especie, puesto que la realidad ya no podría ser pensada nunca más desde un rasgo puntual, sincrónico, vacío, unilateral, un rasgo como si estuviera por fuera de la propia realidad, una realidad dinámica, en devenir, que fluye, histórica, en libertad y a veces caótica, una realidad que atraviesa todos los referentes: los realismos, los idealismos se desmoronaban a finales del siglo XIX, y con ellos se desmoronaba toda una cosmovisión, todo un modo de entender las cosas. Las categorías de sustancia y sujeto dejaban el paso a nuevos modos más de experiencia de lo que es la realidad y el hombre.

Pero tampoco la realidad podía ser dicha de un modo en que ella misma quedaba escindida y en tal escisión se levantaba la dualidad de lo sensible que buscaba ser juzgada y en ello sintetizada por algún carácter de aparente universalidad; un decir, que en verdad, no tocaba a la cosa misma, pues se colocaba metodológica y críticamente por fuera de ella a dictar lo que ella era o, lo que de ella debíamos esperar o, lo que ella tenía que ser para el hombre, etc. ¡Esto ya no es posible!... La gran crítica nietzscheana se lo había llevado todo. Pero, ¿qué le quedaba al europeo? ¿Un mero «positivismo» como la única herramienta con la cual se pueden levantar las ciencias sociales? ¿Era el positivismo ese «Gallo» que nos despertaría o por el contrario nos hundiría más y más en el abismo? El positivismo, como ya lo sabemos, no era nada más y nada menos que una «relación de medida», una regla que permitía medir al hombre; y como para medir, utilizando la regla, siempre se necesitan dos: el hombre se volvía en el duplo sujeto-objeto; y nacía la «realidad» como eso que «está ahí ante» el sujeto fuente de toda medición, de todo conocimiento; la realidad, así escindida, se volvía en objeto de cuantificación y, por ende, funcionaba como el horizonte de objetivación en donde el hombre experimenta lo que es. Sin embargo, esta era la antípoda misma del propio Nietzsche en su crítica radical a la civilización occidental. Todo era platonismo o, si se quiere, platonismo vulgar; en el fondo, nihilismo, voluntad de nada, de negación de la vida, de la vida inmanente, en el propio presente, con su Sí que la afirma incluso en el No del dolor. En Nietzsche no hay positivismo alguno, no hay «relación de medida».

¿Cómo es posible pensar filosóficamente después de Nietzsche? ¿Cómo es posible la filosofía después de Nietzsche? ¿Cómo es posible la metafísica? ¿Cómo la teoría del conocimiento? ¿Cómo es posible el tema de Dios? En definitiva, ¿cómo es posible pensar el problema de Dios sin positivismo desde ese horizonte «bruscamente» esculpido por el martillo nietzscheano?

Nietzsche señalaba que solamente creería en un «dios bailarín»; tras ese tipo de Dios anda Zubiri caminando de modo muy errático en su juventud pero muy honestamente. 


\section{2. ¿Filósofo o sacerdote?}

Un joven filósofo, que ha llegado a Madrid proveniente del País Vasco, Euskadi, que todavía no cumple los 24 años y que está ordenado como sacerdote es Zubiri. El extracto que inicia nuestro texto en el segundo acápite está tomado de una larga carta de 13 folios que Zubiri envió al Obispo de Madrid don Leonardo Eijo y Garay el día 19 de marzo de 1922. El motivo de la carta, en síntesis, es buscar la comprensión del monseñor ante las graves acusaciones que se han vertido sobre él (de un amigo-discípulo), acusaciones que han llevado al Obispo a excomulgar a Zubiri, pues sus herejías son de las más graves (no se podía ser un creyente y un «modernista» a la vez); la carta cuenta su propia e íntima vida y señala el calvario que ha sido para él cargar con la cruz de su propia fe en tiempos que la duda lo corroe y en tiempos que la deuda hacia sus padres y su sociedad le impide rectificar el camino (como debiera haberlo hecho desde muy joven), pero no se siente con las fuerzas para salirse del sacerdocio y se mantiene ahí por largos años.

¿Por qué Zubiri no puede creer de buena fe en Jesús? ¿Para qué filósofos creyentes en tiempos de sordo ateísmo? ¿Por qué no puede dejar esa vida poco afortunada y que lo tortura día a día? ¿Qué sucede con el pensamiento que no puede expresar la experiencia de un hombre creyente? ¿No existe una filosofía que aborde el problema del fundamento desde otra perspectiva más acorde a lo sentido por Zubiri? Recordemos lo que nos dice en su carta tan íntima y dolorosa: «Se nos pone como modelo a Jesús, y hay que tener un poco de buena voluntad para creer que aprecia la vida presente quien dice que no tiene donde recostar su cabeza».

¿Por qué el testimonio de sus padres no son fundamentos para fortalecer la propia fe de Zubiri? ¿En qué ha fallado la enseñanza de Zubiri a lo largo de los años que en el fondo no han permitido que él pueda creer de todo corazón y con entera y sana convicción? ¿Por qué Zubiri no puede estar en paz consigo mismo mientras no esté en paz con la realidad? ¿Es la filosofía la que sembró la duda en el sacerdote español? ¿Fue Kant? ¿El modernismo? ¿Su propia debilidad de carácter para enfrentar a sus padres, amigos, etc.? ¿Hay otra filosofía que lo vuelva a enraizar pero de otro modo más radical, más corporal?

Si damos por hecho la buena fe, que siempre por lo demás debemos dar como hecho para entender e interpretar acabadamente a un autor ( $\mathrm{y}$ a lo que sea), de las palabras de Zubiri. Y si creemos que realmente él quiere creer pero no puede, y se siente como un muerto en vida, pero sin las fuerzas de enmendar su vida radicalmente por el temor de no poder enfrentar ni a sus padres, ni a su sociedad y sobre todo a sí mismo, 
entonces quedémonos en lo dicho anteriormente en esta carta y tomemos la primera sentencia del texto: «El Evangelio toma ante la vida presente una actitud de desprecio para no mirar más que a la vida futura». Y ahora tengamos presente la última sentencia de ese extracto de la carta: «La vida no debe organizarse en fúnebre comitiva que se dirige a la eternidad; la vida es una conquista de la felicidad inmanente».

Si leemos con calma y serenamente, ¿no vemos el espíritu de Nietzsche en estas palabras? Nietzsche, al final de su vida cuando ya estaba dejando el mundo de la cordura, nos decía con fría claridad: «El concepto "Dios", inventado como concepto antitético de la vida - en ese concepto, concentrando en horrorosa unidad todo lo nocivo, envenenador, difamador, la entera hostilidad a muerte contra la vida» (Nietzsche, 1980: 131). Y a veces con vehemencia nos señalaba: «El concepto de Dios -Dios como Dios de los enfermos, Dios como araña, Dios como espíritu- es uno de los conceptos de Dios más corruptos a que se ha llegado en la tierra; tal vez represente incluso el nivel más bajo en la evaluación descendente del tipo de los dioses. ¡Dios, degenerado a ser la contradicción de la vida, en lugar de ser su transformación y su eterno sí! ¡En Dios, declarada la hostilidad a la vida, a la naturaleza, a la voluntad de vida! ¡Dios, fórmula de toda calumnia del "más acá", de toda mentira del "más allá”! ¡En Dios, divinizada la nada, canonizada la voluntad de nada!» (Nietzsche, 1990: 43).

¡He ahí el problema del horizonte del nihilismo! El fundamento se volvió en mero concepto (en parte de un tramado lógico al servicio del poder) y se vació de «corporalidad», de experiencia. ¿Cómo es posible pensar después de Nietzsche y en esa Europa en tránsito, en camino hacia ningún lugar? ¿Cómo ese Dios-Nada, negador de la vida, anti-vida puede enraizar al hombre? ¿Cómo ese Dios sustancia, concepto que funciona como el conocimiento que nos juzga, volviéndonos culpable, y que se juzga a sí mismo nos puede indicar algo a nosotros? ¿Cómo un Dios construido como sustancia desde el juicio se nos puede volver en un problema? ¿Cómo ese Dios positivo, esto es, horizonte de objetividad, trama de nihilidad, relación de medida de todo lo que hay puede indicarnos hacia donde transitamos? ¿Cómo es posible el hombre, cualquier hombre, Zubiri en Europa a comienzos del siglo XX? ¿Cómo es posible el hombre y el mundo a comienzos del siglo XX? En definitiva, ¿cómo es posible Dios? ¿Un Dios que no me sea indiferente, fríamente indiferente?

Zubiri es muy claro cuando señala tajantemente que al ser ordenado sacerdote el 21 de septiembre de 1921 sentía el paso de la nada por su vida; ésta se vaciaba: «Nunca he sentido mayor indiferencia que ese día» 
(Carta de Xavier Zubiri a L. Eijo y Garay, 19-3-1922) (Corominas \& Vicens, 2006: 120).

¿Cómo es posible no sentir más esa indiferencia que suena casi de tipo sartreana? Es posible simplemente como «problema», pero, ¿cómo se piensa el problema si nos hemos quedado sin nuestros «utensilios conceptuales», sin nuestras herramientas que hemos utilizado por siglos para pensar las cosas, al hombre y a Dios mismo? Estamos en aporía, Zubiri estaba en existencial aporía. No sabía qué hacer. No sabía a dónde mirar. No podía salir del abismo. No encontraba la salida al Laberinto de la modernidad. No podía ser feliz. La creyó ver en Kant, en los modernistas, en las ciencias sociales (en especial francesas), en Ortega, en las ciencias naturales, en sus infatigables y numerosos estudios siendo muy joven, pero, en verdad, no encontraba la salida a siglos de laberinto de modernidad. Creemos que «En torno al problema de Dios», el artículo de 1935, fue la salida. Antes del tema de la realidad, estaba el tema del hombre, de un hombre que ya no es entendido como sujeto, yo, conciencia; de un hombre que describe simplemente como Dasein, como lo abierto por excelencia, antípoda del yo (y su cerrazón ontológica): «El Dasein existe. El Dasein es, además, el ente que soy cada vez yo mismo. Al Dasein existente le pertenece el ser-cada-vez-mío como condición de posibilidad de la propiedad e impropiedad... Ahora bien, estas determinaciones del ser del dasein deben ser vistas y comprendidas $a$ priori sobre la base de la constitución de ser que nosotros llamamos el estar-en-el-mundor. ${ }^{5}$.

Un Dasein que constitutivamente se muestra como un estar-en-elmundo (In-der-Welt-sein), pero que está siendo de modo radicalmente único en el mundo porque está implantado en él; esta inflexión del pensamiento de Heidegger es la gran contribución de Zubiri: no solamente se está en el mundo sino que para estarlo precisamente se debe ya estar implantado en él; la propia apertura está puesta como tal y constituye mundo: «El problema de Dios no es una cuestión que el hombre se plantea como un problema científico o vital, algo que en última instancia podría o no ser planteado, sino que es un problema planteado ya en el hombre por el mero hecho de hallarse implantado en la existencia» (Zubiri, 2002: 227).

5 «Dasein existiert. Dasein ist Ferrer Seiendes, das je ich selbst bin. Zum existierenden Dasein gehört die Jemeinigkeit als Bedingung der Möglichkeit von Eigentlichkeit und Uneigentlichkeit... Diese Seinsbestimmungen des Daseins müssen nun aber a priori auf dem Grunde der Seinsverfassung gesehen und verstanden warden, die wir das In-der-Welt-sein nennen» (Heidegger, 2006: 53). Véase, Heidegger (1997: 79). 
En cierta forma, Zubiri de la mano de Heidegger salió de su túnel oscuro y aparentemente sin salida. Un túnel que ni el propio Heidegger vio claramente cómo podía salir. Y que a él mismo lo sumergió por años y lo extravió; ni su propia filosofía lo alcanzaba para poder salir del todo. Zubiri sale tempranamente del túnel de la mano de Heidegger y su pensamiento que emerge de modo más explícito desde Sein und Zeit de 1927 y su visión del hombre como Dasein, existencia y ésta expresamente mundo, inespecífica, pero Heidegger no se pudo dar la mano a sí mismo para salir del propio horizonte del nihilismo. Y Heidegger hizo y rehízo su propia filosofía desde Sein und Zeit en adelante. Pero ese es otro asunto a estudiar. «En torno al problema de Dios», el artículo zubiriano, fue la salida, es decir, la religación, que es la clave del texto porque mienta la implantación misma de la existencia que abre mundo, fue la salida al nihilismo y de allí su filosofía de la realidad en tanto sustantividad (no sustancia ni sujeto) y en tanto inteligencia sentiente (no juicio) como momentos que se levantan desde el horizonte heideggeriano que permiten pensar el fundamento de otro modo no conceptual ni realista ni idealista.

Zubiri estaba en crisis permanente de fe; pero su crisis no es solamente su crisis personal, ésta es el reflejo individual, social e histórico de una Crisis, de una crisis que toca a Europa ya en 1922; crisis de posguerra, de pos-siglo, de pos-positivismo, esto es, de pos-historicismo y psicologismo desde la mano del método científico. Una crisis que toca muy hondo al ser humano, así como lo tocaba a él mismo, pues lo pone en cuestión en lo más radical de su realidad. Una realidad que no se deja categorizar en el horizonte de la sustancia (ni del sujeto) y que no se deja decir desde el logos apofántico. Ni el pensamiento de Aristóteles ni el pensamiento de Kant, en todas sus modalidades y caras a lo largo de la historia del pensamiento occidental, pueden dar con la realidad. ¡Ya no! Todo eso ha sido como ha dicho Nietzsche la «Historia de un Erron». Y, entonces, nos hemos quedado en aporía, pues cómo podemos hablar del hombre, cómo del mundo y en definitiva cómo de Dios. Dios no tiene que tener nada que ver ni con la sustancia ni con el juicio. Si hay Dios, si se da Dios, si acontece la experiencia Dios, si se apropia Dios en cada uno de nosotros dejando al hombre en lo más propio de sí, esto es, en su libertad que lo constituye estando mortalmente en el mundo, entonces no podemos nombrarlo desde el horizonte ni del realismo ni del idealismo. Dios no puede ser ningún tipo de ente, de cosa, de objeto que «esté ahí» ante nosotros. Ante «eso» es imposible creer; Dios no es «concepto» de ninguna especie. ¿Quién cree en un Dios de la objetividad que se dé como horizonte de inteligibilidad para que el hombre se vuelva hombre? Pero tampoco Dios puede ser un fondo oscuro, que esté como 
lo que no se puede sentir y que se postula desde el fideísmo de algo necesario, que todo lo inunda, por ser lo de suyo inefable y excedente del hombre. Luego ¿cómo pensar a Dios, si lo hay, si se da, allende la sustancia, allende el juicio? Esta fue la tarea de Zubiri a lo largo de su vida: «Mi vida intelectual ha transcurrido como una corriente bordeada y encauzada por dos riberas. Una, la idea de liberar el concepto de realidad de su adscripción a la sustancia. Las cosas reales no son sustancias sino sustantividades. [...] La otra ribera es la de liberar la intelección, la inteligencia, de la adscripción a la función de juzgar, por lo menos para mí personalmente, ponerme en marcha en materia filosófica» (Corominas \& Vicens, 2006: 704).

Estas palabras las pronunció Zubiri en público, con casi 85 años, el 15 de mayo de 1983 para la presentación de los libros Inteligencia y logos e Inteligencia y razón. Ya había pasado unos sesenta y dos años de la carta de Zubiri al obispo de Madrid Eijo y Garay. Y después de tanto tiempo ¿qué había sido lo que dio con cierta serenidad a este espíritu en permanente crisis llamado Xavier Zubiri? Lo que sucedió, dicho de forma tajante y clara, fue lo que se sintetizó, se plasmó por primera vez en el artículo «Entorno al problema de Dios» de 1935 en Revista de Occidente. Desde este problema pudo luego liberarse tanto de la sustancia como del juicio.

Si la vida intelectual de Zubiri acontecía dinámicamente como liberación, entonces ¿de qué se liberaba? ¿Cuál era la liberación? ¿Cómo acontecía esto? No es poco liberarse del carácter de sustancia, pues éste tiene tal carga semántica depositada a lo largo de los siglos que se volvía casi una tarea titánica. ¿Cómo pensar sin el carácter sustancial? ¡Esa era la tarea más difícil!... Y el otro problema tan o más radical que el de la sustancia era ¿cómo pensar? ¿Cómo pensar de un modo no judicativo? ¿Es posible pensar sin juzgar y en ello no buscar el conocimiento que necesita ser fundamentado? Así es como Zubiri vivía aislado y en constante problematicidad a lo largo de toda su vida.

\section{La crisis del Fundamento}

«Mis ideas cada vez más inclinadas a lo que pudiéramos llamar el borde de lo admisible, colocaban mi espíritu en crisis continua», Carta de Xavier Zubiri a L. Eijo y Garay (19-3-1922) (Corominas \& Vicens, 2006: 713).

El espíritu de Zubiri vive en crisis permanente. ¿Por qué? Son sus ideas las que lo llevan de un lado para otro; las ideas más propias de este joven sacerdote lo están destrozando, esto es, su talante netamente 
filosófico (talante que les cuesta entender a algunos críticos de Zubiri a la hora de leer ciertos aspectos de la vida personal del autor). La problematicidad de sus ideas irrumpe en su vida. Pero, ¿qué es el carácter de «problema»? ¿En qué consiste lo «problemático»? Lo dice claramente en ese bello trabajo de 1933 «Sobre el problema de la filosofía», publicado en dos números de Revista de Occidente (115 y 118). Este trabajo está en clave eminentemente heideggeriana, pero con tintes muy propios de este joven filósofo:

El horizonte hace posible el sentido en cuanto tal, y en él adquieren sentido, aun tiempo, las cosas y el hombre. Entonces, sólo entonces, puede el hombre ir a buscar cosas, porque el hombre que existe extrañado entre ellas ha comenzado a "ver" y "entender". Sólo cuando ha comenzado a ver y a entender ha podido tropezar con algo que "no se ve bien". Lo oculto, lo encubierto, en cuanto tal, sólo es posible dentro de un campo visual, y sólo entonces puede el hombre proponerse "verlo bien", al descubierto, cara a cara. La delimitación, justamente porque limita, encubre, y porque encubre, puede hacer des-cubiri, esto es, llegar a la verdad, a la aletheia. Sólo entonces puede el objeto presentarse como "nuevo", como "difícilmente" compatible con los demás, como "contradictorio" consigo mismo: es la contradicción que hay en verlo, sin verlo; en verlo cubierto por los demás. Así es posible el 'problema'; así es posible que algo sea problema para una época (Zubiri, 2002, págs. 28-29).

Este texto aunque no lo nombre Zubiri está pensado íntegramente desde Heidegger. Y no solamente desde Sein und Zeit de 1927, sino que creemos que está pensado desde el curso que Zubiri tomó de Heidegger entre 1928-1929 titulado: Introducción a la filosofía. Pues es allí donde Heidegger empieza ya a trabajar en su Kehre, ante sus propios alumnos y amigos, y para ello tiene que dar un «paso atrás» en el mismo análisis existencial del Dasein. No es suficiente solamente describir al Dasein como existente, esto es, como siendo un único en el mundo mortalmente (Sein und Zeit); sino lo que se tiene que pensar es el horizonte mismo del tiempo en donde se da el Dasein únicamente como siendo en el mundo (no olvidemos que la Tercera Sección, titulada Tiempo y ser, de la Primera Parte de Ser y tiempo, Heidegger nunca llegó a escribirla, no lo podía hacer desde el análisis existencial; y en ella era, en esta Tercera Sección, donde se cumplía desde el inicio de la Primera Parte la orientación que constituía al libro mismo). La Primera Parte de Ser y tiempo se titula: «La interpretación del Dasein por la temporeidad y la explicación del tiempo como horizonte trascendental de la pregunta por el ser». Lo único que está en el libro de Heidegger, libro inconcluso, esto nunca lo podemos olvidar cuando analizamos esta gran obra, es «La 
interpretación del Dasein por la temporeidad» (como estar en el mundo y como mortal), pero «La explicación del tiempo como horizonte trascendental de la pregunta por el ser» que corresponde a la Tercera Sección fue lo que no se escribió y era lo más decisivo de toda la obra; era lo que le daba su sentido más propio.

Sin embargo, ¿cómo pensar esto que de inmediato se nos olvida, se nos oscurece, se nos vuelve opaco, se encubre por el mero hecho de estar siendo en el mundo? El paso atrás comenzó siendo por el tema de la verdad (de allí la conferencia de Heidegger: De la esencia de la verdad y todos los estudios acerca de la verdad que realizó en la década del 30); el Dasein existe, nos dice en el parágrafo 12 de Sein und Zeit. «El Dasein es un ente que en su ser se comporta comprensoramente respecto de este ser. Con ello queda indicado el concepto formal de existencia. El Dasein existe» (Heidegger, 1997: 79). Pero existe porque de antemano el Dasein está a la luz de la verdad; es ella la que eminentemente existe; ella es formalmente pura salida, pero en tanto que tal se encubre ${ }^{6}$.

Creemos que Zubiri entendió el giro heideggeriano; incluso más, asistió a él y lo vio en los propios cursos del filósofo alemán. Y este giro hacia la verdad es lo que ve Zubiri como un giro hacia el fundamento; desde donde se implanta la existencia. Es por eso que creemos que Zubiri le puso una nota al pie a este pasaje de la verdad y el problema en «Sobre el problema de la filosofía». La nota dice: «De este sentido de la verdad como descubrimiento ha hecho Heidegger el centro sistemático de toda su ontología, tal como se halla ya desarrollada (en forma muy amplia, bien que aún incompleta), en Sein und Zeit, 1927, pp. 212-230. Su pensamiento puede resumirse así: La verdad 'existe'» (Zubiri, 2002: 29).

Zubiri en esta nota se refiere obviamente al parágrafo 44 de Sein und Zeit (lo cita por su propia edición alemana que tenía ${ }^{7}$ ): Dasein, Erschlossenheit und $W$ abrheit. Es el parágrafo de la verdad como aletheia, donde Heidegger comienza a señalar ese momento radical que tiene la verdad que en su mostrarse se oculta. Si antes Heidegger nos decía el «Dasein existe» ahora se ha puesto más radical y es la verdad la que «funda» la existencia. La «verdad existe», «esencia al Dasein como existencia». Pero si nos damos cuenta con detención, lo dicho por Zubiri, que está en la base de la religación y a ese modo de implantación del hombre en el mundo, es su propia interpretación de lo que está sucediendo con el pensamiento heideggeriano; más que una mera

\footnotetext{
6 Véase, por ejemplo, el excelente Capítulo Tercero de Introducción a la filosofía titulado: «Verdad y Ser. De la esencia original de la verdad como desocultamiento» (Heidegger, 2001: 77-131).

Heidegger (1927). En la traducción corresponde a Heidegger (1997: 233-250).
} 
constatación de cierto pasaje de Sein und Zeit (el pasaje «en torno al problema de la verdad»), pues en tal pasaje no se dice del todo lo que indica el pensador español, pero sí en el curso de 1928-1929 Introducción a la filosofía podemos ver cómo Heidegger está realizando un esfuerzo titánico de pensar desde el análisis existencial de Sein und Zeit algo, que en el fondo, no se deja pensar en ese tipo de análisis; pues es "problemático» pensarlo así. En este curso es el propio Heidegger el que señala que: «La verdad existe, es decir, su forma de ser es lo que llamamos Existenr, existir, y ésta es la forma en que (o como) algo así como existencia o Dasein es» (Heidegger, 2001: 163).

Este texto que es fundamental para nuestra interpretación pareciera que es de Zubiri, pero es de Heidegger. Y creemos que cuando Zubiri asiste a este curso ya tuvo todo lo necesario para comenzar a gestar su propia filosofía de la experiencia de Dios. Es Heidegger el que está pensando desde el giro hacia el propio fundamento que da al Dasein su carácter de existencia; Zubiri dirá implanta a la existencia (la religación).

De allí que Heidegger vea como necesaria la «destrucción de la historia de la filosofía», que parte con la propia destrucción de Sein und Zeit, como único medio posible para dar un «salto» (Sprung) de otro modo a un pensamiento radicalmente distinto, a veces lo llama poético, como única salida viable a la aporía misma de la escritura que paralizó desde dentro de sí misma a Sein und Zeit. Heidegger asistía con su propio libro en la medida que trabajaba en él a los límites mismos del pensar occidental, por lo menos eso es lo que piensa él del pensamiento que se intentó abrir en su libro ya célebre, pero que fracasó en su intento.

$Y$ si nos percatamos, aquí ya radica qué es pensar «en torno al problema...», es el nuevo modo de pensar que interroga en repetición (Wiederholung), cuando la fenomenología ya no puede más, se tiene que repetir la experiencia originaria, pero cómo se hace esto, repensando históricamente la verdad misma, pero la verdad no es algo que porta ciertos contenidos más o menos «profundos»; la verdad no es ninguna tabla de normas originarias y eternas. La verdad está pensada en su radicalidad como desvelamiento (Unverborgenheit). Por esto se dice tajantemente por Heidegger desde la década del 30 en adelante: la verdad existe, existe como historia del ser, historia de envío, de modos de ser. No es que lo dicho en Sein und Zeit sea erróneo, nunca se ha dicho eso sino que es inesencial. Es todavía «ontoteología». Pues el Dasein existe porque la verdad existe. Heidegger lo muestra así en el curso de 19281929; lo señala de modo interrogativo: «Y, ¿qué clase de acontecimiento tiene que producirse, es decir, qué es lo que pasa, qué es lo que tiene que pasar, para que el ente venga a parar en un ocultamiento, venga a quedar oculto?, ¿en qué forma "es" este ocultamiento del ente, con el que tiene 
que pelear todo conocimiento en tanto hallazgo de la verdad, en tanto que descubrimiento del no-ocultamiento, es decir, en tanto que descubrimiento del quedar algo desoculto, es decir, en tanto que poner al descubierto el no ocultamiento, en tanto que descubrir un no ocultamiento?» (Heidegger, 2001: 88).

Heidegger ha dado el paso atrás, hacia la verdad misma que en su «verdadear» da al Dasein su estar en el mundo. Y este desplazamiento dinámico del Dasein desde su estar en el mundo a su verdad es lo que mienta toda esta dialéctica de lo claro-oscuro, del encubrimientodesvelamiento del problema. Problema es el nombre mismo como se siente la aporía misma de la verdad en su movimiento retráctil (Verbaltenheit), que como existe, como se da, se cubre en razón de dar al Dasein su propio ser, su estar en el mundo como mortal.

Problema y verdad son dos nombres para nombrar ese paso atrás en el Dasein mismo, de este Heidegger que gira sobre sí mismo; es un paso si se quiere a su fundamentación (a lo físico diría Zubiri) que de algún modo está sentida en el instante mismo que se está en el mundo siendo. $\mathrm{Y}$ este es el carácter problemático de la verdad que tiene totalmente «perturbado» a Zubiri. Lo tiene casi en el delirio, en el dolor permanente. ¿Cómo pensar después de la crítica nietzscheana y sin sustancia ni juicio? ¡Aquí ya lo vemos con claridad! En ese carácter de problema se mienta la verdad en lenguaje de este Heidegger, Zubiri allí mismo ve a Dios. Pero ya no es un Dios que se dice como sustancia y en un decir judicativo que funciona como Deus ex machina para todos los sistemas filosóficos; sino un dios-experiencia, un dios-verdad, un dios-problema. «En torno al problema», es en torno al problema de la verdad, en torno al problema de Dios. Y pensar en torno al problema de Dios es repensar, repetir la experiencia originaria de fundamentación del hombre. El hombre no solamente está arrojado en el mundo sino que tiene que estarlo, esto es, está implantado en el mundo tendiendo que estar en él. O sea, Shakespeare no tiene la razón del todo; esto es, no se trata simplemente de la aporía de ser o no ser de Hamlet, sino que se trata que antes de decidir ya estamos implantados en la decisión misma. Aquí Zubiri ha visto la salida, de la mano de Heidegger, como lo hemos dicho, se ha dado cuenta de que la puerta ha estado siempre abierta, pero no la había visto (ese es el carácter de verdad, de un Dios que se da como lo que está en la implantación, esto es, lo problemático).

Luego tenemos que «entorno al problema...» es el modo mismo de pensar que ya no es el de Husserl y su fenomenología, sino que es de este Heidegger en su propia crisis que vive en Freiburg (que ya venía de muy joven y se acentúa en Marburg y que podemos en ciertos aspectos ver como similar a la de Zubiri; en cuanto «al problema de Dios»). Y este 
modo de pensar, que es en torno al problema, de inmediato lanza al hombre a un detrás de sí mismo, por decirlo de alguna manera, y ese detrás de sí mismo mienta la verdad, y allí mismo ve Zubiri la posibilidad radical de interrogación por Dios. Como lo plenario mismo que está siendo en la implantación del hombre que existe. Si pensar es pensar en tanto en torno al problema, ese pensar piensa en torno al problema de la vedad en Heidegger y en Dios en Zubiri. Y esto mismo es la religación: «El problema de Dios es el problema de la religación» (Zubiri, 2002: 227).

Creemos que la religación es, si se quiere, la primera idea filosófica de Zubiri en su madurez (cuando publica el artículo en el año 1935, Zubiri tiene 36 años); una idea que atraviesa toda su vida, ya que de allí se pensará la realidad como formalidad y la inteligencia como actualidad más adelante. $\mathrm{Y}$ desde esta idea matriz que es la religación, que nace desde «aguas propiamente heideggerianas» de pensamiento, es como Zubiri deja la crisis (su crisis personal); ahora puede estar en paz consigo mismo, con su mundo, y puede después sinceramente creer en Dios. Pues: «El hombre no sólo no es nada sin cosas [Heidegger de Sein und Zeit de 1927], sino que por sí mismo no "es". No le basta poder y tener que hacerse. Necesita la fuerza de estar haciéndose. Necesita que la hagan hacerse a sí mismo. Su nihilidad ontológica es radical; no sólo es nada sin cosas y sin hacer algo con ellas sino que por sí solo no tiene fuerza para estar haciéndose, para llegar a ser [Heidegger de Einleitung in die Philosophie de 1928]» (Zubiri, 2002: 224).

Desde la carta a L. Eijo y Garay han pasado 13 años en la vida de Zubiri y esos años no han pasado en vano. ¿Qué ha pasado durante ese período? Ha pasado, entre otras cosas, como lo hemos visto: ¡Heidegger! Ha sido el tránsito de Heidegger por la vida de Zubiri. Un Heidegger en Freiburg, un Heidegger único haciendo clases como nunca nadie las hizo antes que él en Alemania. Es «el Mago de Messkirch», como llamaba Karl Löwith a Heidegger, el que hizo entrada en la problemática vida de un Zubiri atormentado y en continua crisis de fe; y fue quién le dio el horizonte por donde enfrentar sus propios temores e inseguridades. Esos temores en un temple anímico como el de Zubiri se podían combatir solamente por medio de la filosofía y ella no estaba a la altura de los tiempos. Fue Heidegger el que la llevó a sus límites y le abrió al pensamiento una nueva posibilidad, la que Zubiri llamó primariamente «religación». 


\section{E1 problema de Dios}

En 1935 Zubiri publica en Revista de Occidente, N 149, el ya célebre texto «En torno al problema de Dios». Es este texto el que luego se extiende en 1936, en Roma, para su publicación en Recherches philosophiques, pero que Zubiri desestimó por encontrar la traducción totalmente horrorosa. El texto ampliado es el que aparece luego en 1944 en Naturaleza, Historia, Dios (NHD) y es el texto que ya se ha convertido en todo un clásico. El texto en NHD se amplía, en especial, en el parágrafo II donde se puede ver claramente la raíz heideggeriana de la religación como también su diferencia, pero una diferencia con Sein und Zeit.

Quedémonos en el texto incipiente de 1935, pues no podemos realizar en este artículo un trabajo detallado y crítico de ambos textos para señalar las variantes entre ellos y qué sería lo propiamente filosófico que se actualiza en NHD (texto que es de 1936). Miremos el texto en algunos aspectos a la luz de ese joven Zubiri que vivía constantemente en crisis.

¿Por qué Zubiri no cree del todo? ¿Qué pasa con su creencia? ¿En qué cree? ¿Cómo cree? ¿Cómo no puede creer con la formación que ha tenido desde su infancia? ¿En qué radica el problema que angustia a Zubiri por varios años? Son muchas preguntas que intentaremos resolver en este artículo, pero que ya hemos indicado anteriormente. El texto de Revista de Occidente consta de treinta páginas y se divide en siete apartados, cada uno muy bien articulado con el antecesor. Escrito el trabajo con mucho cuidado se puede ver una organización lógica explicativa del texto que no deja grietas a la argumentación a favor de otro modo de enfrentar el tema de la existencia de Dios, pues formalmente disuelve esta dificultad acerca de probar ya a favor ya en contra si Dios existe. Y lo disuelve en este modo de pensar en torno al problema de Dios. Este nuevo modo de enfrentar el problema es, en definitiva, el único modo en que el propio Zubiri puede creer. Puesto que su crítica a la religión ha sido radical, tanto como la de Nietzsche, y es una crítica que se mueve en la articulación: hombre y Dios; tal articulación no se deja trazar en categorías ni realistas ni idealistas ni fenomenológicas, etc. Pues todas ellas no han salido del todo del problema de la sustancia y del juicio (lo que Zubiri llama en Inteligencia sentiente como «entificación de la realidad» $\mathrm{y}$ «logificación de la inteligencia»).

Veamos un detalle del texto que es crucial para ver explícitamente cómo Zubiri resuelve no solamente el problema de Dios, sino el problema de la filosofía y, lo más importante, su propio problema de inquietud permanente en la problematicidad misma de la vida: «La vida, 
en su totalidad, no es un simple factum; la presunta facticidad de la existencia es sólo una denominación provisional. Ni es tampoco la existencia una espléndida posibilidad. Es algo más. El hombre recibe la existencia como algo impuesto a él. El hombre está atado a la vida [...] Atados a la vida, no es sin embargo, la vida la que nos ata. Siendo lo más nuestro, puesto que nos hace ser, es, en cierto modo, lo más otro, puesto que nos hace ser» (Zubiri, 2002: 224).

Y Heidegger señala rotundamente en el curso de 1928: «La existencia es esencialmente en la verdad» (Heidegger, 2001: 163). El filósofo alemán es más explícito en el parágrafo 28 titulado «Verdad óntica y verdad ontológica. Verdad y transcendencia de la existencia» (Heidegger, 2001: 216-227). Este parágrafo creemos que es muy importante para entender a Zubiri en el comienzo de su filosofar de la mano de Heidegger y la religación, pero será un inicio que permanecerá toda la vida en el pensamiento del filósofo español, hasta la conceptuación de la realidad como formalidad de realidad o formalidad de actualidad. Por ejemplo, allí se nos indica: «... en la esencia de la existencia o Dasein radica un sen-en-la-verdad más original, o a la inversa: la esencia misma de la existencia o Dasein debe ser aprehendida de forma aún más radical atendiendo a esta verdad más original que representa la comprensión del ser, de forma tan radical que podamos decir: el hombre es aquel ente cuya esencia, es decir, a cuya constitución o estructura de ser o índole de ser, pertenece esencialmente algo así como Seinsverständnis, es decir, algo así como comprensión del ser... La Existenz o el existir sólo es posible en su raíz en (y a través de) la comprensión del ser» (Heidegger, 2001: 217-218). El Dasein tiene raíz en la verdad misma, es ella que en su ocultarse permite, deja libre el espacio mismo del Dasein. Es el Dasein a la luz de lo que da el «ahí» $(D a)$ mismo de su ser para existir. Esta articulación es lo que está mentando la religación. Zubiri lo señala así: «...el hombre, al existir, no sólo se encuentra con cosas que "hay" y con las que tiene que hacerse, sino que se encuentra con que "hay" que hacerse y "ha" de estar haciéndose. Además de cosas "hay" también lo que hace que haya» (Zubiri, 2002: 225).

Zubiri trabaja en la senda misma abierta por Heidegger, pues el filósofo alemán lo indica de la siguiente forma: «Tenemos que tratar de aprehender en su esencia la proto-acción (o acción original) del dejar-ser el ente, es decir, tenemos que preguntar por su base, por su más íntima posibilidad, para poder hacernos alguna idea acerca de qué es lo que pasa en tal proyectar el ser. A tal fin vamos a empezar arrojando provisionalmente y desde lejos alguna luz sobre ese abismo» (Heidegger, 2001: 219). 
Heidegger ya estaba en lo mismo, tratando de iluminar ese abismo (Abgrund) para ver cómo esa proto-acción es la que libera, deja espacio para que el hombre en su existir sea, esté siendo en el mundo. A esto es lo que llama Zubiri «lo que hace que haya». La religación versa acerca de ese «hace que haya», esa proto-acción que abre al hombre desde su ser para que sea en el mundo, y lo sea como iluminador de él. Zubiri es más arriesgado que Heidegger. Su vehemencia lo lleva de inmediato a ver en este carácter de la religación a Dios, pero no es un Dios de fundamentación teológica-filosófica; esto para nada es lo que piensa Zubiri. La verdad, la religación da el paso atrás del pensamiento que indaga por el hombre que es, que existe en facticidad, que es en el mundo por estar arrojado, pero que se siente, se comprende como dejado ahí en lo abierto, como implantado en el mundo. En la religación se desliza Dios, en la verdad originaria se desliza la nada de ente, el abismo. Zubiri lo dice así: "Y así como el estar abierto a las cosas nos descubre, en este su estar abierto, que "hay" cosas, así también el estar religado nos descubre que 'hay' lo que religa, lo que constituye la raíz fundamental de la existencia. Sin compromiso ulterior, es, por lo pronto, lo que todos designamos por el vocablo Dios, aquello a que estamos religados en nuestro ser entero» (Zubiri, 2002: 226).

Si nos damos cuenta Zubiri ha dado sutilmente un paso más que Heidegger, el paso del Abismo a Dios. ¿Es legítimo este paso? Creemos que para la radical inquietud en la que vivía Zubiri en este paso más allá se jugaba su propia existencia. No podía seguir esperando y dejando que aconteciera la radicalidad misma del Abismo; en el propio Abismo sonaba ya lo más propio que nos acontece y nos apropia aquí y ahora; y nos apropia en plena libertad. A lo mejor ya estaba incoado en estos años, entre 1928 al 1935 no solamente el pensamiento maduro de Zubiri en torno a la realidad como formalidad del «de suyo», del «de suyo» en actualidad, sino que ya sonaba cercanamente el Ereignis (que Heidegger explícitamente muestra en 1936 en los Beiträge), pero esto es otro asunto a estudiar (Espinoza, 2008).

\section{Conclusión}

¿Qué mienta «En torno al problema de Dios»? ¿Qué nos indica la biografía de Zubiri? Al parecer se resuelve en la medida que comprendamos qué nos señala el carácter de «problema».

Si viajamos con la imaginación y nos transportamos a Freiburg a comienzos de 1930, veremos que Zubiri está inquieto, no se siente bien; está incómodo en el «mundo heideggeriano», pues radicalmente no es 
«su» mundo (Zubiri tendrá que construir el propio; lo que también se le vuelve tortuoso). Heidegger es una gran «figura» filosófica, así como lo era Ortega para los españoles. Pero en el caso de Heidegger ser una «figura» reconocida en todo Europa lo había llevado rápidamente a la cumbre del Olimpo no solamente de las ideas sino sobre todo de la vanagloria. El filósofo alemán vive en la distancia y es inaccesible para muchos (también para su propia familia); entre ellos Zubiri. Heidegger ya se entiende a sí mismo con el Minotauro que vive en el Laberinto.

Ante este panorama, Zubiri se decide, por una parte, a marcharse de Freiburg, pues en Berlín puede encontrar la ciencia que necesita para fortalecer el pensamiento desde la rigurosidad de este saber (un saber que está pasando por uno de los momentos más importantes de la historia) y, por otra parte, a escribir una carta a Heidegger para mostrarle su malestar. No puede entender cómo una vida, la de Heidegger, puede disociarse entre la filosofía y la cotidianidad. Él no busca interés informativo, ni curiosidad al estar al lado de Heidegger; él busca al filósofo, que como tal, puede abrir el mundo desde otro modo de pensar, pero un mundo en el diálogo, en la palabra, en la acogida con el otro.

Esta carta que envió Zubiri a Heidegger el 19 de Febrero de 1930 (Corominas \& Vicens, 2006: 212-214) tiene un tono un tanto de reproche y frustración, pero a la vez es cercana y busca en un último momento, ante la eminente partida hacia Berlín, la posibilidad de dialogar (Heidegger al leer la carta de inmediato invitó a cenar a su casa a Zubiri, fue una cena de despedida; Espinoza, 2004); se dice en ella cómo un sincero afecto, por su parte, no ha podido fraguar una amistad de corazón entre ellos y esto, en gran medida, porque el distanciamiento del filósofo alemán es radical. En esta carta, Zubiri se sincera y señala de sí mismo un aspecto que es fundamental para interpretar su pensamiento y que indica la senda de nuestra interpretación:

Durante toda mi vida... sólo he conocido una emoción que me ha conmovido: la emoción del puro problematismo. Desde muy joven he sentido dolor de ver cómo todo se transforma en problema. Pero este dolor no era en sí mismo doloroso... Más bien este dolor era la fuente, en el fondo la única fuente hasta ahora, de verdaderos gozos. Me aferré positivamente a este carácter problemático de la existencia (Carta de Zubiri a Heidegger, 19-2-1930) (Corominas \& Vicens, 2006: 54).

El asombro de Zubiri que lo mueve a filosofar no es el griego; tampoco el medieval y menos el moderno. Es el propio problematismo de las cosas el que lo tiene en tensión. Ese problematismo es el que lo ha 
llevado a resolver la gran aporía en que estaba él, su tiempo, su mundo. La aporía nietzscheana de cómo es posible filosofar sin sustancia y sin juicio se disuelve, finalmente en la vida de Zubiri, transitando por Freiburg y de allí cobra incipiente cuerpo en la religación, que es un primer estadio en su lenta pero rigurosa marcha conceptual durante décadas, la que terminará brillantemente con la formalidad de realidad en los años ochenta. Y es en la religación donde Zubiri se vuelve hacia Dios, se vuelve con fe verdadera. No es un Dios sustancia, no es un Dios que se dice desde el juicio; es un Dios que tiene algo de «bailarín», algo de la experiencia radical que nos implanta en la existencia. Si Heidegger se quedó en el Abismo, Zubiri da el paso necesario de ir transitando en el Abismo... Es posible que la vehemencia que mueve a Zubiri a «caminar sobre el Abismo» sea por el temor de haberse consagrado a la nada. Como lo indicábamos al inicio de este escrito, en esa tremenda carta que alguna vez escribió Zubiri siendo muy joven:

Cuando oí que el Obispo nos invitaba a dar el paso decisivo me adelanté sin titubear; nos prosternamos ante el altar; se cantaron sobre nosotros las letanías de los santos: el gran error de mi vida estaba consumado. Tenía miedo de haber sacrificado mi vida a la nada.

\section{REFERENCIAS}

-Ascorra, P. \& Espinoza, R. (2011). Cuerpo y alma en Zubiri... Un problema filosófico-teológico. Revista Pensamiento, 67 (254), 1061-1075.

-Corominas, J. \& Vicens, J. A. (2006). Xavier Zubiri. La soledad sonora. Madrid: Taurus.

-Espinoza, R. (2004). “¿Por qué Herr Kollege no ha hablado usted antes”. La crítica de Zubiri a "Sein und Zeit". Cuadernos Salmantinos de Filosofia (31), 201-249.

-Espinoza, R. (2006). Realidad y tiempo en Zubiri. Granada: Comares.

-Espinoza, R. (2008). Heidegger y Zubiri. Después del ser y la realidad: El problema del Ereignis. En R. Espinoza \& J. Nicolás (Eds.), Zubiri ante Heidegger (págs. 197-250). Barcelona: Herder.

-Hegel, G. W. F. (2010). Fenomenología del espiritu (A. Gómez, Trad.) Madrid: Abada.

-Heidegger, M. (1927). Sein und Zeit. Halle a. d. S.: Max Niemeyer Verlag.

-Heidegger, M. (1997). Ser y tiempo (J. E. Rivera, Trad.) Santiago de Chile: Editorial Universitaria.

-Heidegger, M. (2001). Introducción a la filosofía (M. Jiménez Redondo, Trad.). Madrid: Cátedra.

-Heidegger, M. (2006). Sein und Zeit. Tübingen: Max Niemeyer Verlag. 
-Nietzsche, F. (1966). Werke in drei Bänden (Vol. II). München: Verlag Carl Hansen.

-Nietzsche, F. (1980). Ecce homo. Cómo se llega a ser lo que se es (A. Sánchez Pascual, Trad.). Madrid: Alianza.

-Nietzsche, F. (1990). El Anticristo (A. Sánchez Pascual, Trad.). Madrid: Alianza.

-Nietzsche, F. (2006). Fragmentos póstumos (1885-1889) (J. Chamorro, Trad., Vol. IV). Madrid: Tecnos.

-Zubiri, X. (1983). Inteligencia y razón. Madrid: Alianza.

-Zubiri, X. (2002). Sobre el problema de la filosofía y otros escritos (1932-1944). Madrid: Alianza.

Sumario: Introducción; 1. «La duda»; 2. ¿Filósofo o sacerdote?; 3. La crisis del Fundamento; 4. El problema de Dios; Conclusión; Referencias. 